\title{
Female gametophytic mutants of Arabidopsis thaliana identified in a gene trap insertional mutagenesis screen
}

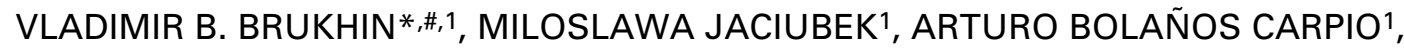 \\ VERA KUZMINA ${ }^{1}$ and UELI GROSSNIKLAUS ${ }^{1}$ \\ ${ }^{1}$ Institute of Plant Biology and Zürich-Basel Plant Science Center, University of Zürich, Switzerland
}

\begin{abstract}
In plants, the male and female gametophytes represent the haploid generation that alternates with the diploid sporophytic generation. Male and female gametophytes develop from haploid micro- and megaspores, respectively. In flowering plants (angiosperms), the spores themselves arise from the sporophyte through meiotic divisions of sporogenous cells in the reproductive organs of the flower. Male and female gametophytes contain two pairs of gametes that participate in double fertilization, a distinctive feature of angiosperms. In this paper, we describe the employment of a transposon-based gene trap system to identify mutations affecting the gametophytic phase of the plant life cycle. Mutants affecting female gametogenesis were identified in a two-step screen for (i) reduced fertility (seed abortion or undeveloped ovules) and (ii) segregation ratio distortion. Non-functional female gametophytes do not initiate seed development, leading to semi-sterility such that causal or linked alleles are transmitted at reduced frequency to the progeny (non-Mendelian segregation). From a population of 2,511 transposants, we identified 54 lines with reduced seed set $(2 \%)$. Examination of their distorted segregation ratios and seed phenotypes led to the isolation of 12 gametophytic mutants, six of which are described herein. Chromosomal sequences flanking the transposon insertions were identified and physically mapped onto the genome sequence of Arabidopsis thaliana. Surprisingly, the insertion sites were often associated with chromosomal rearrangements, making it difficult to assign the mutant phenotypes to a specific gene. The mutants were classified according to the process affected at the time of arrest, i.e. showing mitotic, karyogamic, maternal or degenerative phenotypes.
\end{abstract}

KEY WORDS: Ds transposon, female gametophyte, segregation ratio distortion, sexual plant reproduction

\section{Introduction}

It is very difficult, often impossible, to identify and characterize genes involved in basic cellular processes in diploid higher eukaryotes as organisms with a homozygous mutation in an essential gene are lethal. The study of haploid plant gametophytes provides an excellent opportunity to examine such genes essential to cell division or other fundamental cellular processes. Heterozygous recessive mutations are not lethal to the diploid tissues of the sporophyte, such that their lethal phenotype can be characterized in 1/2 of the haploid gametophytes that are produced by a plant heterozygous for a gametophyte lethal mutation.

In seed plants the life cycle alternates between a dominant diploid phase (sporophyte) and a strongly reduced haploid phase (gametophyte). In angiosperms, the haploid female gametophyte (embryo sac) is generated by the functional megaspore, the only surviving meiotic product, through three mitotic divisions. The female gametophyte typically consists of only seven cells, two female gametes (egg and central cell) and five accessory cells. It is highly inaccessible because it develops inside the ovule, deeply embedded within the gyneocium of the flower (Grossniklaus and Schneitz, 1998; Drews et al., 1998, Yadegari and Drews, 2004). The male gametophtye (pollen) is even more reduced and usually consists of only three cells, two of which are sperm cells. Seed development is initiated by double fertilization, where the pollen

\footnotetext{
Abbreviations used in this paper: Ac, Activator; Ds, Dissociation; DIC, differential interference contrast; GUS, $\beta$-glucoronidase; GT, gene trap; TAIL-PCR, thermal asymmetric interlaced polymerase chain reaction; iPCR, inverse polymerase chain reaction.
}

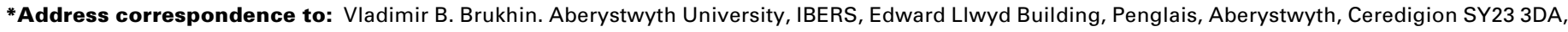

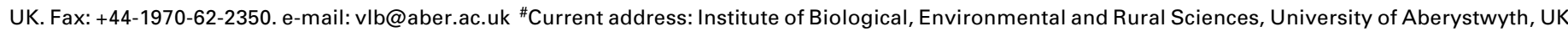


tube enters the embryo sac and releases the two sperm cells. One sperm cell fuses with the haploid egg cell to produce a diploid zygote, which initiates embryo development and constitutes the next sporophytic generation. The second sperm cell fuses with a homo-diploid central cell, initiating the development of the triploid endosperm that provides nourishment to the developing embryo (Olsen, 2004). This complex developmental process is unlike any found in animals, where the meiotic products directly differentiate into the gametes. In contrast, the meiotic products of plants undergo several mitotic divisions to form a multicellular haploid organism with distinct cell types, including the two pairs of gametes. This collection of haploid cells provides a short window of opportunity to identify genes involved in cellular processes fundamental to their survival or playing a role in their specific developmental regulation. A viable diploid sporophyte heterozygous for a mutated essential gene will produce $50 \%$ viable (wildtype) haploid gametophytes and 50\% abnormal (mutant) haploid gametophytes. This unique feature of plants allows genes essential to an organism's survival to be dissected, since mutants are characterized by the developmental stage at which they are arrested. Arabidopsis thaliana is the organism of choice to study such lethal mutations since it has a short life cycle, excellent tools for forward and reverse genetics, and produces a large number of gametophytes (reviewed in Page and Grossniklaus, 2002).

Up to the mid 1990s few molecular or genetic studies had been made on female gametophyte development and only a single female gametophytic mutant had been described in Arabidopsis (Redei, 1965). This lack of knowledge led Jack Heslop-Harrison to suggest that the gametophyte was "the forgotten generation" (Heslop-Harrison, 1979). Over the last two decades emerging new genetic and bioinformatics tools have allowed exploiting a functional genomics approach to dissect female gametophyte development and to identify the specific genes involved. Significant progress has been made using insertion mutagenesis to provide tools for forward and reverse genetic studies. For instance, valuable mutant populations of Arabidopsis have been generated, using systems designed to create low copy number transposon insertions at random positions in the genome. Such systems provide a physical tag that pinpoints the location of a mutation, which can be used for mapping and as a starting point from which to sequence an insertion site (e.g. Sundaresan et al., 1995, Springer et al., 1995; Moore et al., 1997, Parinov et al., 1999, Zhang et al., 2003, van Enckevort et al., 2005). During the last few years new gametophytic mutants from large-scale insertional mutagenesis projects - using either transposons or T-DNA insertions - have been isolated and loci essential for male and female gametophyte development identified (Moore et al., 1997; Feldmann et al., 1997; Howden et al., 1998; Bonhomme et al., 1998; Christensen et al., 1998, 2002; Grini et al., 1999; Moore, 2002; Lalanne et al., 2004; Pagnussat et al., 2005; reviewed in Brukhin et al., 2005a). Nevertheless, the identification of the developmental pathways and genes that orchestrate female gametophyte function and developmental progression are far from being accomplished.

We have exploited the Activator/Dissociation ( $A c / D s)$ gene trap transposon system developed by Sundaresan and colleagues (1995) to generate new insertions distributed throughout the genome of Arabidopsis. These insertion lines were screened to identify essential genes affecting gametophyte development or function, and their phenotypes were analyzed. Mutations affecting the gametophytic phase of the life cycle were identified in a two-step screen for (i) reduced fertility (seed abortion or undeveloped ovules) and (ii) a distorted segregation ratio of the dominant marker present on the Ds transposon (for details on this strategy, see Moore et al., 1997; Page and Grossniklaus, 2002).

Here we provide a detailed description of six gametophytic mutants showing a stably distorted segregation ratio of the dominant marker present on the $D$ s element and reduced fertility or a semi-sterile phenotype. We provide the genetic and cytological characteristics of these mutants. Based on the cytology of terminally arrested embryo sacs, we classified them as mitotic, karyogamic, maternal, or degenerative phenotypes. For all mutants we describe the phenotype at the morphological and cytological level, genetic segregation, and transmission efficiencies through both male and female gametophytes. Despite a tight cosegregation of the $D$ s elements with the mutant phenotypes, only one of the mutants could be unambiguously assigned to a gene encoding a TATC-like protein, while two are likely associated with rearrangements, and the final three are apparently not tagged as assessed by the analysis of additional insertion alleles. This raises important questions as to the use of insertional mutagenesis in combination with segregation ratio distortion to identify gametophytic mutants.

\section{Results and Discussion}

\section{Insertional mutagenesis creates mutations affecting plant reproduction}

We generated 2511 gene trap (GT) lines, each with putatively a single, independent $D s$ insertion, and screened the progeny derived from self-fertilization of these lines for gametophytic mutants. From all GT lines generated we found 54 (2\%) lines with a reduced seed set.

Deviation from a 3:1 Mendelian segregation ratio of kanamycin resistant $\left(\mathrm{Kan}^{\mathrm{r}}\right)$ to sensitive (Kan ${ }^{\mathrm{s}}$ ) seedlings towards $\mathrm{Kan}^{\mathrm{r}} / \mathrm{Kan}^{\mathrm{s}}$ ratios of less than 2:1 is a characteristic of mutations affecting one or both gametophytes (Feldmann et al., 1997; Moore et al., 1997; Howden et al., 1998). We screened the entire GT population for a distorted segregation ratio of the $\mathrm{Kan}^{\mathrm{r}}$ gene present on the Ds element. $31 \%$ of the GT lines produced seedlings of which all or nearly all were resistant to kanamycin. This could be due either to the homozygosity of the $D s$ insertion or due to the insertion of more than one Ds element per line. $40 \%$ of the lines showed $\mathrm{Kan}^{\mathrm{r}}$ :Kan ${ }^{\mathrm{s}}$ segregation ratios of about $3: 1$, corresponding to a normal Mendelian segregation ratio. $19.5 \%$ of the lines gave reduced segregation ratios in the range $2: 1$ to $2.5: 1$, which are likely to result from a recessive, zygotic embryo lethal phenotype. $9.5 \%$ of the GT lines showed distorted segregation ratios between $2: 1$ and $0.14: 1$. The latter might be caused by a partial or full reduction of transmission of the $D s$ insertion through one or both sexes. In order to learn which of the semi-sterile GT lines showed ovule and/or seed abortion due to reduced transmission through male and/or female gametophytes, we re-examined 54 preselected lines with a reduced seed set for segregation ratio distortion. Finally, we identified 12 GT lines for further investigation, which combined a semi-sterile phenotype with a segregation distortion ratio that matched the prediction for a gametophytic mutation. These lines correspond to $0.48 \%$ of all lines screened. 

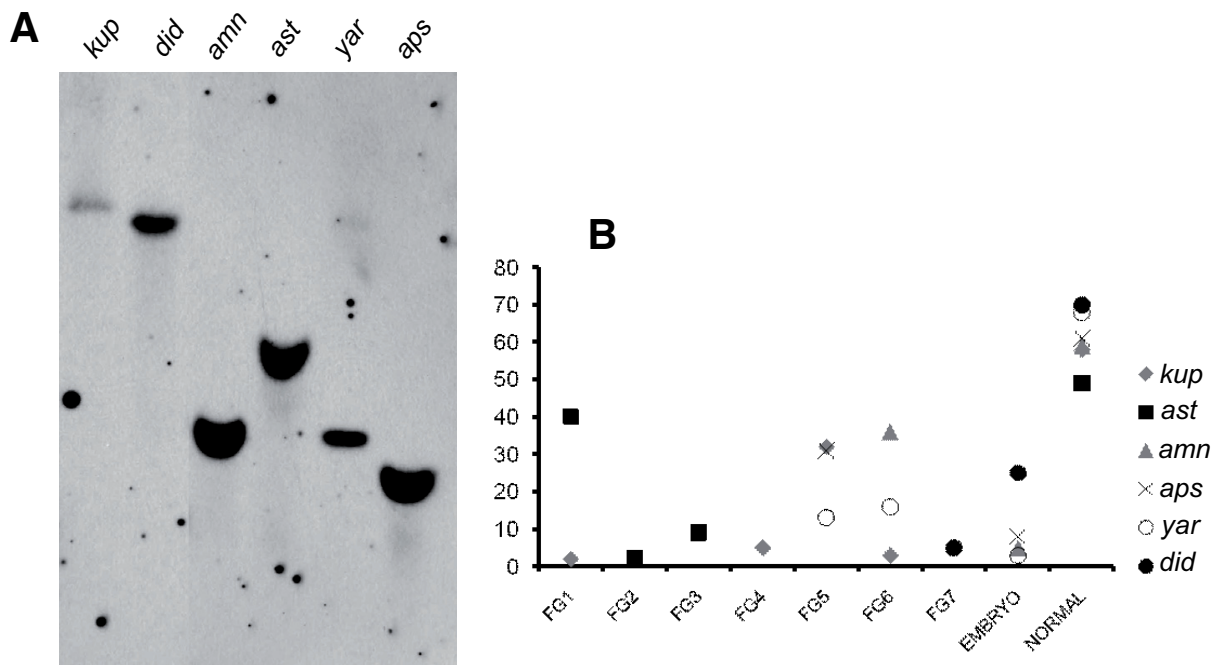

Fig. 1. Confirmation of a single $D s$ insertion per line and summary of the phenotypic characterization of six mutants affecting gametophyte development. (A) Genomic Southern blot indicates the presence of a single Ds element in each mutant tested. For Southern blotting genomic DNA of the respective mutants was restricted with EcoRI endonuclease and a digoxygenin-labelled 5' Ds probe was used to detect the left border fragment. (B) The graph summarizes the percentage of ovules with a terminal phenotype at a particular stage of development for all six mutants. $X$ axis - stages of female gametophyte at which arrested gametophytes were found. Y-axis percentage of arrested ovules/seeds at each stage and normal seeds. FG1, one-nucleate female gametophyte; FG2-F3, two-nucleate female gametophyte; FG4, four-nucleate female gametophyte with unfused polar nuclei; FG6, seven-celled female gametophyte with polar nuclei fused; FG7, four-celled female gametophyte: the antipodal cells have degenerated; FG8, three-celled female gametophyte: one of the synergid cells degenerates and the mature female gametophyte consists of the egg cell, the central cell, and one persistent synergid cell; stages after Christensen et al. 2007.

This frequency is within the range obtained in other screens aimed at identifying gametophytic mutations (Feldmann et al., 1997; Moore et al., 1997; Howden et al., 1998; Bonhome et al., 1998; Lalanne et al., 2004; Pagnussat et al., 2005).

In this study, we report on the six of these mutants with phenotypes predominantly affecting female gametophyte development or function. We named these mutants after gods or goddesses from various Pantheons whose influence is exerted, according to legend, upon fertility and reproduction.

\section{Gametophytic mutants generally affect transmission through both sexes}

Self-crossed progeny of all six mutants showed stable segre- gation ratio distortion over at least three to four generations, suggesting that the mutations in the lines under study were associated with the $D s$ insertion. However, a distortion in the segregation ratio among the progeny from a self-cross does not provide insights into which sex is affected by the mutation. Although we specifically focused on mutants that showed reduced fertility - and thus expected them to have a defect in female gametophyte development or function - these mutants may also affect the male gametophyte to some extent.

To quantify the transmission efficiency through either sex we measured the $D s$ inheritance in reciprocal crosses to the wild type. Southern blot analysis was carried out to investigate whether the genome of each GT line did contain only one Ds element, as

TABLE 1

\section{PHENOTYPE, GENETIC SEGREGATION AND TRANSMISSION ANALYSIS OF THE GAMETOPHYTIC MUTANTS}

\begin{tabular}{|c|c|c|c|c|c|c|c|c|c|c|c|}
\hline Mutant & Phenotype & $\begin{array}{l}\text { Seeds } \\
\text { Scored }\end{array}$ & $\begin{array}{c}\text { Segregation } \\
\text { Kan }^{r}: \text { Kan }^{s}\end{array}$ & $\begin{array}{l}\text { Seeds } \\
\text { Scored }\end{array}$ & P-Value & TEF & $\begin{array}{l}\text { Seeds } \\
\text { Scored }\end{array}$ & TEM & Seeds Scored & Ds insertion site & Disrupted gene function \\
\hline Kupalo & $58 \% \mathrm{~N}+42 \%$ UO & 1302 & $1.04: 1$ & 161 & 0.81 & $40 \%$ & 424 & $68 \%$ & 275 & At2g01070 & PTM1-like protein \\
\hline Astlik & $49 \% \mathrm{~N}+51 \% \cup \mathrm{O}$ & 570 & $1.66: 1$ & 187 & 0.23 & $61 \%$ & 46 & $98 \%$ & 107 & $\begin{array}{l}\text { Deletion of } \\
\text { At3g03030 } \\
\text { At3g03040 } \\
\text { At3g03050 } \\
\text { At3g03060 } \\
\text { Ds 3'-end } \\
\text { At1g75990 }\end{array}$ & $\begin{array}{l}\text { F-box family protein } \\
\text { F-box family protein } \\
\text { Cellulose synthase-like protein AAA-type ATPase family protein } \\
\text { AAA-type ATPase family protein } \\
\text { RPN3b subunit of } 26 \text { S proteasome } \\
\text { EMBRYO DEFECTIVE } 2719\end{array}$ \\
\hline amon & $59 \% N+36 \% \cup O+5 \% A$ & 1030 & $1.13: 1$ & 194 & 0.39 & $56 \%$ & 426 & $24 \%$ & 31 & At4g02700 & \\
\hline apis & $61 \% N+31 \% \cup O+8 \% A$ & 1045 & $0.32: 1$ & 212 & NA & $5 \%$ & 113 & $8 \%$ & 232 & At5g44520 & \\
\hline yarilo & $68 \% N+29 \% \cup O+3 \% A$ & 1221 & $0.30: 1$ & 341 & NA & $15 \%$ & 109 & $9 \%$ & 146 & $\begin{array}{l}\text { Ds 5'-end } \\
\text { At2g34680 }\end{array}$ & AIR9 auxin-induced in root cultures \\
\hline $\begin{array}{l}\text { Didilia } \\
\text { (apg2) }\end{array}$ & $70 \% \mathrm{~N}+5 \% \mathrm{UO}+25 \% \mathrm{~A}$ & 1010 & $1.05: 1$ & 254 & 0.71 & $34 \%$ & 270 & $59 \%$ & 195 & At2g01110 & TATC-like protein, UNFERTILIZED EMBRYO SAC3 \\
\hline wt & $93 \% \mathrm{~N}+6 \% \cup \mathrm{O}+1 \% \mathrm{~A}$ & $844^{\mathrm{a}}$ & $3: 1^{D}$ & & - & $100 \%$ & & $100 \%$ & & --. & \\
\hline
\end{tabular}

abased on data from Moore et al., 1997

bexpected, ideal values

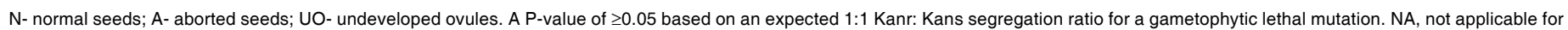

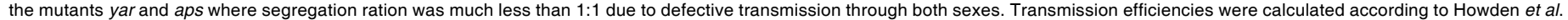
(1998): TE=Kan'-/ Kans x 100\%; Kan', kanamycin-resistant seedlings; Kan ${ }^{\mathrm{s}}$, kanamycin-sensitive seedlings; TEF- female transmission efficiency, TEM- male transmission efficiency. 
multiple insertions would confound the analysis. As shown in Fig. $1 \mathrm{~A}$ each of the selected six lines contained only a single $D$ s element in its genome. Linkage analysis of 100 to 250 plants from the progeny of each line tested revealed complete co-segregation of the Ds element (i.e. $\mathrm{Kan}^{r}$ ) and the mutant phenotype. These findings indicate that the insertions were either responsible for the observed semi-sterile phenotype or were tightly linked to a mutation responsible for the phenotype.

The efficiency of $D s$ transmission was estimated according to Howden and colleagues (1998). As shown in Table 1, all insertions showed a reduced transmission through the female gametophyte (TEF, transmission efficiency female) as expected, ranging from $5 \%$ to $61 \%$ of the wild-type allele. However, except for one mutant (astlik), all others showed also a reduced transmission of the Ds through the male gametophyte (TEM, transmission efficiency male) ranging from $8 \%$ to $68 \%$ of the wild-type allele. The severity of reduced transmission through male and female gametophytes is correlated (correlation coefficient $R=0.72$ ), indicating that likely some basic cellular functions are affected in

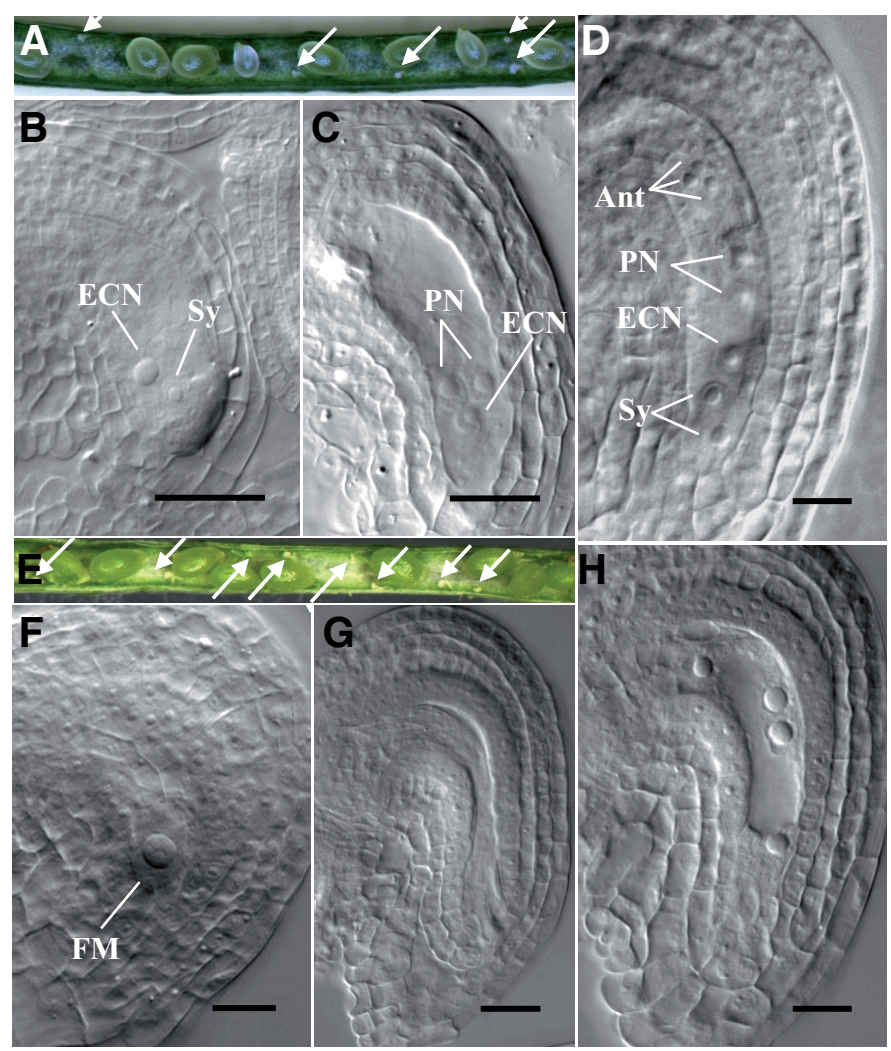

Fig. 2. Embryo sac and seed set phenotypes of the mitotic class mutants kupalo and astlik. (A-C) kupalo, (D) wild-type, (E-H) astlik. (A) Silique containing normal seed and infertile ovules (arrows). (B) Defective synergid cell. (C) Unsuccessful cellularization of the embryo sac with missing synergid nuclei. (D) Seven-celled, 8-nucleate wild-type embryo sac containing an egg cell, two synergids, two un-fused polar nuclei, and three antipodal cells. (E) Silique containing normal seeds and infertile ovules (arrows). (F) Arrested functional megaspore. (G) Arrested ovule lacking an embryo sac but with continued integument growth. (H) Embryo sac arrested at the four-nucleate stage. ECN, egg cell nucleus; FM, functional megaspore; PN, polar nuclei; Ant, antipodals; Sy, synergids. Bars, $10 \mu \mathrm{m}$. these mutants rather than sex-specific developmental processes. Furthermore, segregation analysis of self-crosses of all six mutants did not produce any homozygous plants. This indicates that, in addition to the gametophytic defects revealed in heterozygotes, homozygous mutants are likely zygotic lethal.

In summary, the gametophytic mutants analyzed here generally affect both male and female gametophytes, confirming earlier findings that sex-specific gametophytic mutants are rare (Moore et al., 1997; Feldmann et al., 1997; Howden et al., 1998; Bonhomme et al., 1998; Christensen et al., 1998, 2002; Grini et al., 1999; Moore, 2002; Lalanne et al., 2004; Boavida et al., 2009). This is expected since many events during the process of male and female gametophyte formation are similar and the expression of many essential genes during the haploid phase will be required in both gametophytes.

\section{The kupalo and astlik mutants are defective in mitotic pro- gression}

Two mutants were categorized into the class showing mitotic phenotypes, which are defective in one or several of the three mitotic divisions (FG1 to FG5, according to Christensen et al., 1997) that form the mature embryo sac (Brukhin et al., 2005a). The first mutant was named kupalo (kup), after the Slavic god of herbs, sorcery, sex, and midsummer. The segregation ratio of $\mathrm{Kan}^{\mathrm{r}}$ :Kan ${ }^{\mathrm{s}}$ seedlings derived from kup/KUP plants was 1.04:1 (Table 1). The transmission of $D s$ through the female gametophyte was only $40 \%$, while male transmission was reduced to $68 \%$ (Table 1). Analyses of the kup mutant phenotype showed that in mature siliques $42 \%$ of ovules were unfertilized (Table 1 ), remaining white and small without developing into a seed (Fig. 2A, arrows). Cytological observations under differential interference contrast (DIC) optics revealed that the majority of ovules (32\%) arrested at stage FG5 (Fig. 2B). At this stage, in wild-type ovules the syncytial, eight-nucleate embryo sac cellularizes to form the seven-celled female gametophyte with three antipodals, two synergids, an egg cell, and a bi-nucleate central cell (Fig. 2D). 5\% of the ovules were arrested at FG3-FG4, i.e. the mutant showed pleiotropic defects during the nuclear division phase between the two- and eight-nucleate stage. $2 \%$ of the embryo sacs were arrested at FG1 during the first mitotic division of the functional megaspore, and $3 \%$ of ovules reached FG6, which corresponds to the mature embryo sac (Fig. 1B), but they did not progress beyond. Interestingly, some ovules in kup showed embryo sacs with defective (Fig. 2B) or missing (Fig. 2C) synergids and abnormalities in the polar nuclei (Fig. 2C). Analysis of the mature pollen stained with DAPI indicated that about $12 \%$ of the pollen grains were abnormal in comparison to $5 \%$ in the wild type (Table 2). Defective mature pollen grains had only two nuclei, consistent with a defect in mitotic progression. Defective pollen showed either one weakly stained, vegetative nucleus and one strongly stained, single sperm nucleus, or two weakly stained, elongated nuclei (not shown)

In the kup mutant, the DNA fragment flanking the Ds element corresponded to the second exon of the At2g01070 gene (Fig. 3), which encodes a PTM1-like trans-membrane protein of unknown molecular function (Table 1). This protein is reported to co-purify with late Golgi vesicles, which contribute to cell wall and membrane formation and also deliver regulatory substances; consequently the disruption of such a gene may affect membrane 
properties and cellularization, a process blocked in kup mutant embryo sacs. Only one other insertion within the At2g01070 gene was available, but it showed no obvious fertility defects (not shown). Since we could not confirm the T-DNA insertion site in this second line, it is currently unclear whether the $D$ s disrupting At2g01070 is indeed responsible for the kup phenotype.

The mutant astlik (ast) was named after the Armenian goddess of love and fertility. The $\mathrm{Kan}^{\mathrm{r}}$ :Kan ${ }^{\mathrm{s}}$ segregation ratio in the progeny of ast/AST plants was 1.66:1 (Table 1), i.e. characteristically a combination of zygotic and gametophytic lethality. Female transmission efficiency was reduced to $61 \%$ (Table 1), while male transmission was similar to that of wild-type plants. In mature siliques of the ast mutant $51 \%$ of ovules were unfertilized (Fig. 2E, arrows). Most of these (40\% of the total) were arrested prior to the first mitotic division of the functional megaspore at FG1 (Fig. 2F), while a small number arrested at FG2 (2\%) or FG3 (9\%) - a stage corresponding to the four-nuclear embryo sac (Fig. 2H, Fig. 1B). Despite these abnormalities, the integuments continued to grow and the defective ovules in mature siliques often appeared as shown in Fig. 2G, where no embryo sac can be discerned within the ovule. Assessment of pollen grains in the ast/AST mutant showed that $10 \%$ of the mature pollen grains were abnormal with phenotypes similar to those found in kup (Table 2).

In ast the 5'-end of the Ds was inserted in the sixth exon of the F-box protein gene At3g03030 and 3'-end was found in the fifth exon of At3g03060 encoding a protein similar to the AAA-type ATPase family of proteins (Bayer et al., 2006), thereby probably deleting two other genes, At3g03040 and At3g03050 (Fig. 3). It is therefore not clear which of the deleted gene(s) might be responsible for the phenotype. To possibly link the phenotype to one of the affected genes, we assessed several additional insertion mutants. Exonic T-DNA insertions in At3g03030 (SALK_094197) and At3g03040 (SALK_056065 and SALK_056153) showed no obvious phenotypes. Conversely, an exonic $D s$ insertion in At3g03050 showed a slight reduction in seed set with about $10 \%$ unfertilized ovules (Table 1S). At3g03050 encodes a cellulose synthase-like protein, mutations in which cause root hairs to rupture at their tip soon after initiation (Bernal et al., 2008). This gene is expressed in the embryo sac as shown by genetic subtraction profiling (Johnston et al., 2007). However, two other exonic insertions in At3g03050 showed no fertility phenotype (not shown), making it unlikely that this gene is responsible for the ast phenotype. Disruption of the At3g03060 promoter region (SALK_1304_B10) was associated with $8 \%$ unfertilised ovules and $15 \%$ aborted seeds in mature siliques (Table $1 \mathrm{~S}$ ). This gene encodes a protein of the AAA-type ATPase family (Bayer et al., 2006). However, since a second exonic T-DNA insertion shows no obvious phenotype (not shown), At3g03060 is probably not responsible for gametophytic lethality in the ast mutant.

In addition to the small deletion on chromosome 3, we found a 3'-end of Ds on chromosome 1 in the sixth exon of At1g75990, encoding the $26 \mathrm{~S}$ proteasome regulatory subunit RPN3b, which participates in ubiquitin-dependent protein catabolic processes (Vierstra, 2003; Smalle and Vierstra, 2004; Yang et al., 2004) essential to gametophyte development (Gallois et al., 2009) and the proper execution of mitosis in all eukaryotes (Den Elzen and Pines, 2001; Vierstra 2003; Smalle and Vierstra, 2004; Yang et al., 2004, Brukhin et al., 2005b). Given that we could not amplify the 5' end of the $D s$, that only a single $D$ s element was detected in this line (Fig. 1A), and that the segregation ratio of $\mathrm{Kan}^{\mathrm{r}}$ is consistent with a single insertion (Table 1), we conclude that only a short piece of the 3'-end of the Ds is present on chromosome 1. In contrast the $D s$ insertion on chromosome 3 appears to be associated with a deletion, as was reported for several other lines that were generated using this transposon system (Oh et al., 2003; Page et al., 2004, Boavida et al., 2009).

Given the complex rearrangements observed in ast, it is not yet possible to assign the defect to a particular gene. However, because the mutant shows a mitotic arrest, it may well be that the mutation in RPN3b plays a major part in the ast phenotype. Although individual insertions into At3g03030 and At3g03040, which both encode F-box proteins, have no obvious phenotypes, their simultaneous disruption may contribute to the mitotic class phenotype seen in astmutants. F-box proteins are components of SCF ubiquitin-ligase complexes that function in binding substrates for ubiquitin-mediated proteolysis (Kipreos and Paqano, 2000). Ubiquitin-mediated removal of regulatory proteins controlling the cell cycle is important for normal mitotic progression and their disruption may thus lead to mitotic arrest, possibly in conjunction with the disruption of $R P N 3 b$ in the ast mutant.

\section{The amon and apis mutants affect karyogamy}

Mutants of the karyogamy class affect the fusion of polar nuclei. During normal development, these nuclei migrate from opposite poles of the embryo sac towards the centre, where they fuse prior to fertilization to form the homo-diploid nucleus of the central cell. A characteristic of many karyogamic mutants is a gametophytic maternal-effect followed by seed abortion. In the

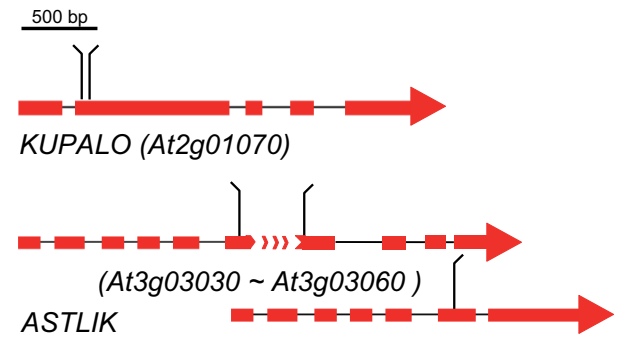

(At1g75990)

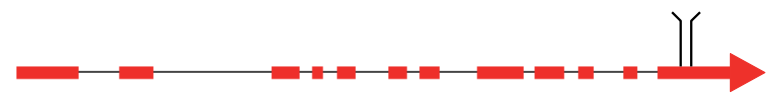

AMON (At4g02700)

\}

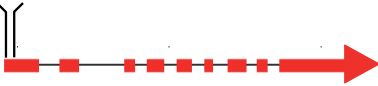

APIS (At5g44520)

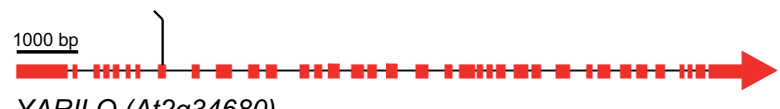

YARILO (At2g34680)

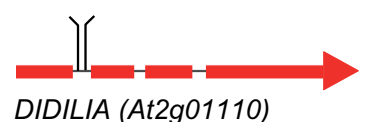

Fig. 3. Schematic representation of $D$ s element insertion sites. The intron-exon structure of the disrupted genes is shown. 3'-and 5'-ends of the inserted Ds elements are indicated by vertical lines ticked to the left and right, respectively. 


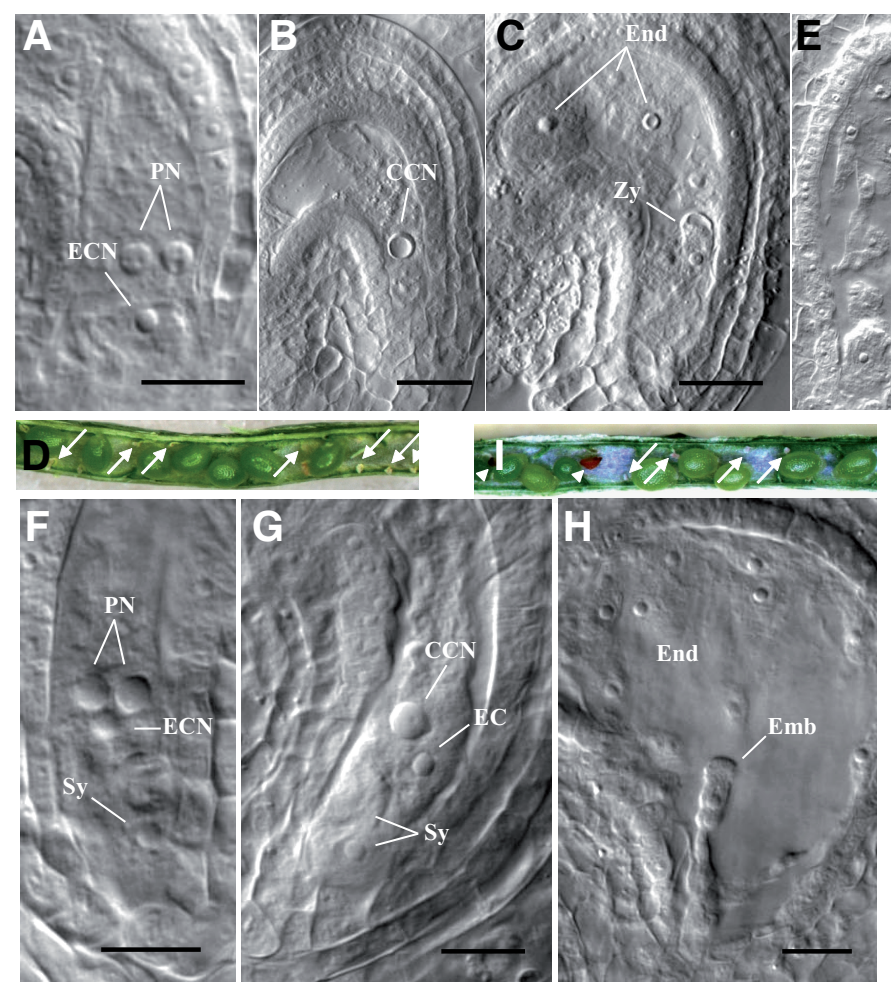

present study we report two gametophytic mutants, amon (amn) and apis (aps), which fall into this category.

The mutant amon was named after the Egyptian god of fertility. Among the progeny of $a m n / A M N$ mutants $\mathrm{Kan}^{\mathrm{r}}: \mathrm{Kan}^{\mathrm{s}}$ segregates in a ratio of $1.13: 1$ and transmission efficiency was severely reduced through both the male and female gametophytes (TEF $=56 \%$, TEM=24\%; Table 1). Mature siliques of heterozygous amn/AMN plants contained 59\% normal seed, 36\% white, unfertilized ovules, and 5\% brown, early aborted seeds (Fig. 4D). The majority of ovules (over $30 \%$ ) contained abnormally enlarged, unfused polar nuclei (Fig. 4A) or, if the polar nuclei had fused, the central cell nucleus had initiated degeneration (Fig. 4B). These mutant ovules were found in siliques alongside normal seeds that either contained a mature embryo sac or occasionally an early stage embryo, which had undergone a few divisions together with developing endosperm (Fig. 4E). In summary, the white, unfertilized ovules of amn (36\%) arrested between stages FG5 and FG6 (Fig. 1B), while the brown, early aborted seed (5\%) arrested at the zygotic stage (Fig. 4C) or during embryo development after a few cell divisions (not shown). About $10 \%$ of the mature pollen grains displayed a defect: $3 \%$ contained only a single nucleus (Fig. 5 BC), while the remaining $7 \%$ had two nuclei, similar to what was observed in kup and ast (Table 2).

In amn the Ds element was inserted in the 12-th exon of At4g02700 encoding a sulfate transporter 3;2 (Fig. 3), which is thought to be responsible for the uptake and translocation of sulphate through the cell membrane (Takahashi et al., 2000) and whose expression is enriched in the embryo sac (Johnston et al., 2007). The assessment of eight additional T-DNA insertions within the coding region of $A t 4 g 02700$ demonstrated no fertility phenotypes, however, indicating that this gene is not responsible for the amn phenotype.

Apis (aps) was named after an Egyptian bull deity representing
Fig. 4. Embryo sac and seed set phenotypes of the karyogamy class mutants amon and apis. (AE) amon, (F-I) apis. (A,F) Un-fused polar nuclei in the central cell. (B) Degenerating central cell nucleus. (C) Degenerating zygote, which is elongated but did not divide, surrounded by abnormal endosperm nuclei. (E) Normal wild-type seed with octant embryo and alveolar endosperm - seed from the same silique as the defective ovules shown in $(B, C)$. (D, I) Siliques containing normal seed, infertile ovules (arrows), and aborted seeds (arrowheads) that arrested shortly after fertilization. (G) Unusually large central cell nucleus. (H) Shrunken, degenerating two-cell embryo, endosperm nuclei were uniformly small and undifferentiated. CCN, central cell nucleus; EC, egg cell; ECN, egg cell nucleus; Emb, embryo; End, endosperm; PN, polar nuclei; Sy, synergid; Zy, zygote. Bars, 10 $\mu \mathrm{m}$ in $(A-C)$ and $(F-H)$ and $25 \mu \mathrm{m}$ in (E).

fertility. The $\mathrm{Kan}^{\mathrm{r}}$ :Kans segregation ratio among the progeny of aps/APS mutants was $0.32: 1$ (Table 1 ), indicating that the mutation affects both female and male gametophytes and may cause embryo lethality. Indeed, reciprocal crosses showed that transmission through both sexes was strongly reduced (TEF $=5 \%$, $\mathrm{TEM}=8 \%$ ). Phenotypic assays of seeds in mature siliques of aps/ APS heterozygotes showed that $61 \%$ of seeds appeared normal, while $31 \%$ of the ovules were unfertilized and $8 \%$ of the seeds aborted at early developmental stages (Fig. 4I). Cytological analyses revealed that $31 \%$ of the arrested embryo sacs had unfused polar nuclei at stage FG5 (Fig. 4F), or defects soon after central cell formation at stage FG6 (Fig. 4G). $8 \%$ of the ovules were arrested and aborted soon after the initiation of seed development (Fig. $4 \mathrm{H}, \mathrm{I}$ arrowheads). This might be due to a

TABLE 2

\section{PHENOTYPES IN MATURE POLLEN GRAINS OF GAMETOPYTIC MUTANTS}

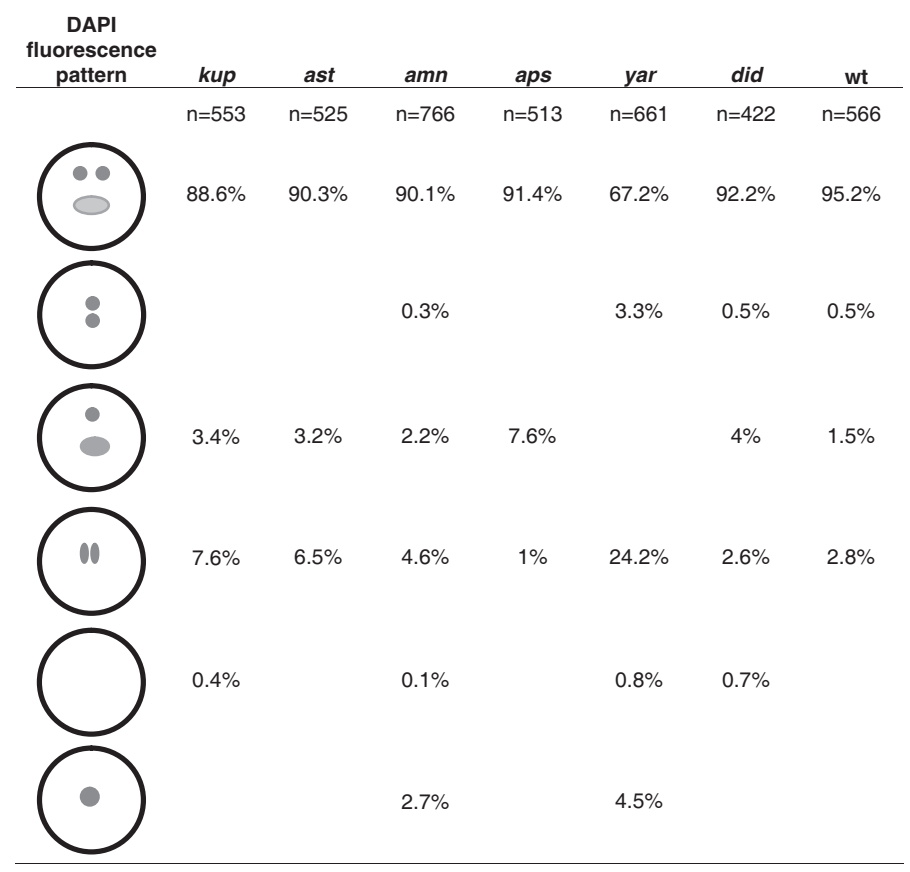

wt - wild type; $n$ - scored pollen grains. For examples of DAPI fluorescence patterns see Fig. 5 . 
gametophytic maternal effect leading to embryo lethality when mutant female gametophytes get occasionally fertilized. Alternatively, aborted seeds could correspond to homozygous mutants showing zygotic embryo lethality. The latter explanation is unlikely, however, as less than $0.5 \%$ homozygous embryos are expected based on the experimentally determined transmission efficiencies. Therefore, we conclude that the vast majority of aborted seeds are caused by a gametophytic maternal effect of the aps mutation. Of the mature pollen grains, $9 \%$ percent were abnormal with the majority showing only one large, weakly stained and one small, strongly stained nucleus (Table 2; Fig. 5D).

In the aps mutant the $D$ s element was found in the first exon of At5g44520, encoding a ribulose 5-phosphate isomerase-related protein (Fig. 3). Scoring five additional T-DNA insertions in At5g44520 (one exonic, one intronic, and three in the promoter region) revealed no obvious phenotypes. Therefore, the aps mutant phenotype is likely not caused by a disruption of this gene.

\section{The yarilo mutant causes the degeneration of central cell, egg cell and synergids}

The degenerative class of mutants show spontaneous abnormal nuclear degeneration during embryo sac development that has dramatic effects on nuclear stability. The yarilo (yar) mutant was named after the handsome, youthful Slavic god of passion, sex, and lust. The yarmutant causes degeneration of embryo sac components. The $\mathrm{Kan}^{\mathrm{r}}: \mathrm{Kan}^{\mathrm{s}}$ segregation ratio of $0.3: 1$ in this mutant indicates an involvement of both gametophytes in the phenotype, as was seen with aps (Table 1). Indeed, the transmission efficiency was very low through both sexes (TEF $=15 \%$, TEM=9\%) (Table 1). Mature yar siliques contained $29 \%$ unfertilized, arrested ovules and 3\% brownish, aborted seeds. Microscopic investigations of the yarmutant showed deformation of the polar nuclei especially in the nucleolus, the most visible component of the nucleus in cleared preparations (Fig. 6B). Cytological observations of yar demonstrated that $13 \%$ of the ovules had large degenerating nuclei, which arrested just prior to the fusion of the polar nuclei at stage FG4-FG5 (Fig. 6A), or soon after fusion at stages FG5-FG6 in 16\% of cases (Fig. 6B, Fig. 1B). Often, we also observed degeneration of the egg cell, synergid, and central cell nuclei. A small proportion of the seeds (3\%) aborted at the two-cell embryo stage (Fig. 6C). This aspect is characteristic of seed abortion effected by the maternal gametophyte but may also be due to zygotic embryo lethality, which is expected to arise at a frequency of about $1.3 \%$. Gametophytic maternal effects were previously observed as late phenotypes of the karyogamy and degenerative class mutants and they may also be features of the mitotic mutant class. Investigations of pollen behaviour in planta revealed that a large number of yar pollen grains failed to stick to the mature stigma (not shown). An observation of pollen grains stained with DAPI demonstrated that almost $33 \%$ of the pollen grains were defective (Table 2 ), with only one strongly stained nucleus in nearly $5 \%$ and two weakly stained, elongated (possibly degrading) nuclei in $24 \%$ of the pollen grains (Fig. 5E), respectively.

In yar, the 5'-end of the Ds element was found in the eighth exon of the AIR9 (AUXIN-INDUCED IN ROOT CULTURES9) gene (At2g34680), which was previously identified in a differential cDNA library screen comparing auxin-treated and non-treated root cultures (Neuteboom et al., 1999). The AIR9 protein associ- ates with microtubules in land plants, where it recognizes the cortical division site during pre-prophase and, later on, the site of cell plate formation during cytokinesis (Buschmann et al., 2006). A Meta-Profile analysis of gene expression using Genevestigator tools (Hruz et al., 2008) indicates that At2g34680 is highly expressed in inflorescence meristems, flowers, stamens, carpels, roots of the mature plant, and at the young rosette, bolting and flowering stages of developing plants. The $\beta$-glucuronidase (GUS) reporter present on the Ds transposon in yarshows strong expression in the roots of young seedlings about two weeks after germination (Fig. 6I), while other vegetative or generative parts of mutant plants showed no GUS activity.

Assessment of additional insertion lines revealed a complex situation, with 3 lines (two exonic, and one in the promoter region) having no obvious phenotype, but one line showing reduced fertility similar to yar. A T-DNA insertion (SALK_113675) in the intron of At2g34680 showed siliques with $22.7 \%$ unfertilized ovules and $1.3 \%$ aborted seeds in heterozygous plants (Table 1S). In a screen for mutants affecting male progamic development the same gene was disrupted in the ungud9 (ung9) mutant, causing reduced male and female transmission efficiencies of $4.2 \%$ and $55.3 \%$, respectively (Lalanne et al., 2004). Given that gametophytic mutant phenotypes often show variable expression and that both yar and ung 9 produce aborted seeds, yar may well be allelic to ung9. However, the 3'-end of Ds in yar could not be isolated by either TAIL-PCR or iPCR, possibly because it was deleted during the transposition process. We do currently not know whether this insertion only disrupts one gene or is also flanked by an adjacent deletion. Given that $A I R 9$ is in the vicinity of the Ds launch site (DsG1; Sundaresan et al., 1995), and that several deletions were created by intrachromosomal excision of a hybrid Ds element from this site (Page et al., 2004), it is possible
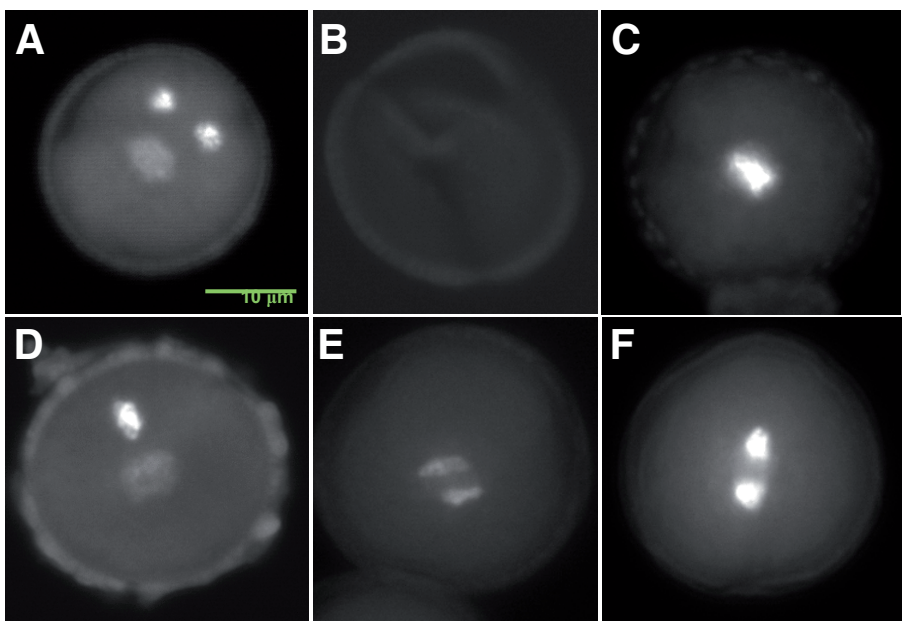

Fig. 5. Patterns of DAPI fluorescence in mature pollen grains. (A) Wild type. (B-F) Defective pollen grains from various mutants. (A) Pollen grain containing a weakly stained, large vegetative cell and two strongly stained, small sperm cell nuclei. (B,C) Pollen grains from amn. (B) No nuclei are detectable in this pollen grain. (C) Only a single, strongly stained nucleus is present in this amn pollen grain. (D) Pollen grain from aps with only one sperm and one vegetative cell nucleus. (E) Two weakly stained, elongated and possibly degrading nuclei are visible in this yar pollen grain. (F) Only two strongly stained sperm-like nuclei are detected in this did pollen grain. 
that ung9 and yar are also deletion mutants. Because of the complex findings with $D$ s as well as T-DNA insertions in $A I R 9$, it is currently not possible to definitively assign the yar phenotype to this auxin-induced gene.

\section{The didilia mutant has a gametophytic maternal post-fertili- zation defect}

In the gametophytic maternal effect class of mutants the phenotype is apparent only at the post-fertilization stage (Grossniklaus et al., 1998, Brukhin et al., 2005a). Seed abortion depends on the genotype of female gametophyte only and leads to maternally derived seed abortion irrespective of the paternal contribution. The mutant didilia (did) was named after the Slavic goddess of female fertility, childbearing, growth and vegetation. The $\mathrm{Kan}^{\mathrm{r}}: \mathrm{Kan}^{\mathrm{s}}$ segregation ratio of $1.05: 1$ was typical for a gametophytic mutation, but transmission of did was reduced through both the female (TEF=34\%) and male gametophyte (TEM=59\%) (Table 1). Mature did siliques contained $25 \%$ aborted seeds, which were either white in immature green siliques (Fig. $6 \mathrm{D})$ or brown and shrivelled in mature siliques. $5 \%$ of the ovules remained unfertilized in the mature fruit (Fig. 6D, arrows). This seed abortion phenotype may reflect incomplete penetrance of the gametophytic mutation. Cytological observations revealed that $5 \%$ of the unfertilized ovules were arrested at the mature embryo sac stage (FG7) (not shown), while $25 \%$ of seeds arrested much later, mainly at the late heart to early torpedo stage of embryo development (Fig. 6F). The remaining $70 \%$ of seeds were normal (Fig. 6E, Fig. 1B). In arrested seeds the endosperm was also blocked at the early alveolar stage (Fig. 6F). DID/did mutant plants produced around $8 \%$ abnormal pollen grains (Table 2 ), with only two nuclei, either with one sperm-like and one vegetative nucleus or with two weakly staining, elongated nuclei. Rarely, two sperm-like, strongly stained nuclei were present (Fig. $5 \mathrm{~F})$.

In did, the first intron of $A t 2 g 01110$ was disrupted by the Ds element (Fig. 3). This gene encodes a Twin-Arginine Translocation C (TATC) protein responsible for thylakoid membrane organization and biogenesis (Motohashi et al., 2001; Allen et al., 2002). TATC is a major component of $\Delta \mathrm{pH}$-dependent protein transporter activity (Yen et al., 2002). The GUS reporter on the Ds element showed strong expression in both seedlings (Fig. $6 \mathrm{H}$ ) and mature plants, including all parts of the flower (not shown). The ovules also expressed GUS (Fig. 6G) and after fertilization, we observed GUS activity in the endosperm but not the embryo (not shown). Assessment of the available expression arrays using Genevestigator tools (Hruz et al., 2008) showed that At2g01110 is expressed in many vegetative and generative organs with a particularly high activity in seeds, embryos, flowers, pedicels, and leaf primordia. During plant development gene expression peaks at the flowering stage. Mutants affecting At2g01110 were also isolated in a screen for seedling lethality (Budziszewski et al., 2001) and the protein has been detected in the proteomes of mitochondria (van der Merwe and Dubery, 2007) and chloroplasts (Zybailov et al., 2008). Other mutants disrupting At2g01110 were previously identified as albino and pale green2 (apg2) (Motohashi et al., 2001) and unfertilized embryo sac3 (une3) (Pagnussat et al., 2005). The latter shows that the gene plays an important role in zygote and endosperm formation after double fertilization (Pagnussat et al., 2005). Analysis of two additional insertion lines,

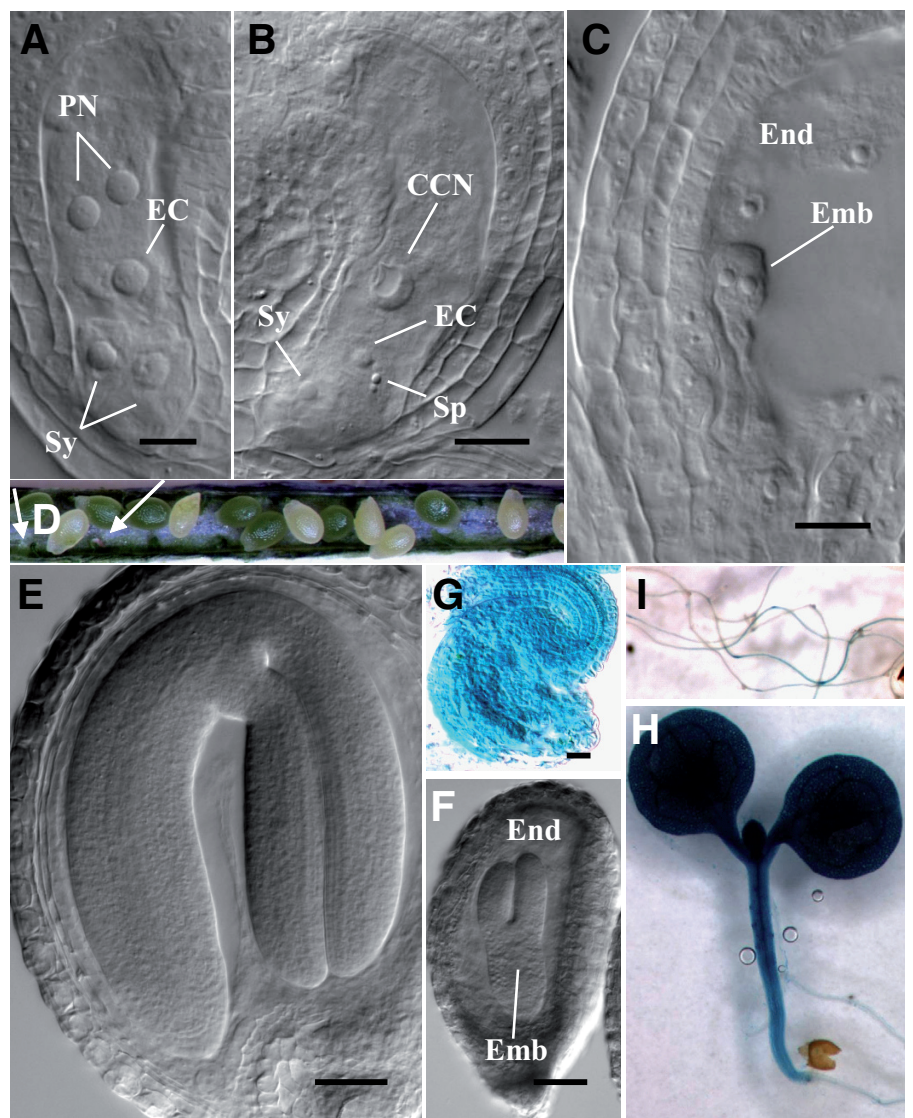

Fig. 6. Embryo sac and seed set phenotypes of the degenerative class mutant yarilo and the gametophytic maternal effect class mutant didilia. (A-C, I) yarilo, (D-H) didilia. (A) Abnormally sized egg cell, synergid and polar nuclei that remain un-fused. (B) Degenerating central cell nucleus and unusually small defective egg cell nucleus. Adjacent to the egg nucleus is a smaller nucleus, probably of a sperm that has failed to fuse with the egg. (C) Shrunk degenerating two-cell embryo in the seed. (D) Siliques containing normal seed, infertile ovules (arrows), and aborting seeds (white). (E) Mature normal seed at the walking stick stage of embryo development from the same silique as shown in F. (F) Aborted seed containing arrested early torpedo stage embryo and under-developed endosperm. (G-I) GUS reporter gene expression under the promoters of the disrupted genes: The gene trap GUS gene was engineered into the Ds, preceded by multiple splice acceptor sites and it has no promoter, so that GUS expression can occur under the promoter of the gene disrupted by the Ds only when GUS inserts within a transcribed chromosomal region, creating a transcriptional fusion. (G) Cleared ovule with ubiquitous GUS expression. (H) Ubiquitous GUS expression in 10-day old seedling. (I) GUS expression in the roots of two-week old seedlings. $C C N$, central cell nucleus; EC, egg cell; Emb, embryo; End, endosperm; $P N$, polar nuclei; Sy, synergid; Sp, sperm. Bars, $10 \mathrm{~mm}$ in (A-C) and (G) and $50 \mathrm{~mm}$ in $(E, F)$.

(GT_5_74422 and GT_5_105311) carrying an exonic Ds element in At2g01110, as well as the analysis of the une3 mutant, revealed fertility phenotypes similar to that of did (Table 1S). Thus, did is likely allelic to apg2 and une3, and the maternal did phenotype can be assigned to a disruption of At2g01110, which is expected to lead to defective plastids and/or mitochondria, which are maternally inherited. 


\section{Mutations reveal pleiotropic effects in gametophyte arrest}

Despite of the small size and limited number of cells constituting the female gametophyte, many cellular processes are involved in its development and function (Grossniklaus and Schneitz, 1998; Yadegari and Drews, 2004; Dresselhaus, 2006). From the six classes of female gametophytic defects recognized in Arabidopsis (Brukhin et al., 2005a), the mutants described in this paper have been assigned to four: the mitotic, karyogamic, degenerative, and maternal effect class. However, despite a prevalent stage of arrest, the phenotype was expressed at variable levels in all mutants (Fig. 1B). It is well documented in previous studies of female gametophytic mutants that developmental progression is rarely arrested at one particular stage in development (Bonhomme et al. 1998; Howden et al., 1998; Grini et al., 1999; Moore et al., 1997; Pagnussat et al., 2005), and that a large number of genes are expressed in the embryo sac (Yu et al., 2005; Johnston et al., 2007; Jones-Rhoades et al., 2007; Steffen et al., 2007; Wuest et al., 2010). Phenotypic variability may be caused by varying degrees of carry-over of mRNA derived from earlier gene expression in the megaspore mother cell and/ or by genetic redundancy in the Arabidopsis genome.

In addition to these difficulties, many gametophytic mutants cause maternal effects that lead to seed abortion. Pagnussat et al. (2005) reported that from 130 female gametophytic mutants examined, about half were found to be defective in post-fertilization processes due to the mutant maternal allele. A similar frequency was found by Moore (2002) in whose study 7 out of 14 female gametophytic mutants showed clear maternal effects. In our study, three mutants revealed a low level of seed abortion (yar. 3\%; amn: 5\%; aps: 8\%) whereas did, which was identified as a maternal effect mutant, showed a high level of seed abortion (did: $25 \%$ ). Late maternal effects that affect the mature seed may explain the discrepancy between the low transmission efficiency and the mild semi-sterile phenotype observed in yar and aps. In these mutants, seeds of normal appearance did not germinate or died immediately after germination (not shown).

An assessment of the defects in mature pollen grains showed that only kup and yar had a significant proportion of defective pollen (kup: $12 \%$, yar. $23 \%$ ) while the rest of the mutants produced only few abnormal pollen grains ( $\leq 10 \%)$. Except for ast, which has wild-type transmission through the male gametophyte, the rare phenotypes in mature pollen grains do not correlate with the strong reduction in male transmission efficiency. Therefore, there have to be defects not only during pollen development but also in the progamic phase (Lalanne et al., 2004), i.e. during pollen tube growth, guidance, or reception.

\section{Gametophytic mutants are often associated with chromo- somal rearrangements}

To our surprise many insertion sites turned out to be complex involving rearrangements, a feature that has often been observed for T-DNA insertions but was so far only rarely associated with $D s$ transposition. The general occurrence of $D s$-associated deletions was estimated to be around 1\% (Page et al., 2004), but the current study on female gametophytic mutants, as well as a recently published study on male gametophytic mutants, in which at least 16 out of 39 Ds insertions were associated with rearrangements (Boavida et al., 2009), show a much higher incidence of chromosomal aberrations resulting from $D$ s transposition. Because large deletions and translocations usually result in reduced gametophytic transmission, screens for gametophytic mutants may strongly enrich for chromosomal rearrangements (Oh et al., 2004; Page et al., 2004; Boavida et al., 2009). Moreover, two of the mutants analyzed with clean Ds insertions (amn and aps, see Fig. 3) turned out not to be tagged by an analysis of several additional alleles. While it is known that $D$ s elements can transpose again after insertion, leaving a footprint that could cause the mutant phenotype, only few such cases have been reported for this system (Grossniklaus et al., 1998; Escobar-Restrepo et al., 2007). Consequently, gametophytic mutants that were isolated using Ds or T-DNA insertional mutagenesis have to be assessed carefully and caution has to be taken when interpreting gametophytic functions based on sequences flanking the insertion sites (Pagnussat et al., 2005; Boavida et al., 2009).

As a result of the aforementioned issues with $D s$-induced mutations, only one of the six mutants described here could unambiguously be assigned to a gene: the maternal effect mutant did, which turned out to be allelic to apg2 and une3, encoding a TACT-like protein (Motohashi et al., 2001; Pagnussat et al., 2005). For two other mutants, ast and yar, genes affected by the $D s$ insertions and the associated rearrangements are likely involved in gametophyte development, since some of the additional insertion alleles analyzed show aspects of the phenotype, but further investigations are required to unambiguously identify the gene(s) responsible for these phenotypes. Finally, amn and aps are clearly not tagged by the $D s$ despite the tight co-segregation. For kup, the identity of the causal gene is completely open because the two alleles available provided divergent results. Further characterization of the genes identified, the isolation of additional alleles, and the production of plants containing multiple mutations, will shed more light on the cellular functions of the biochemical pathways disrupted in the mutants presented here.

\section{Materials and Methods}

\section{Generation of Ds insertion lines and plant growth conditions}

We used the insertional mutagenesis system described by Sundaresan and colleagues (1995) in the wild-type strain of Arabidopsis thaliana (L.) Heynh. var. Landsberg (erecta mutant: Ler). Mutagenesis was initiated by crossing plants homozygous for one $D s$ element to plants homozygous for an immobilized Ac element. Transposants were identified among the F2 seedlings on $0.7 \%$ agar medium (Difco) containing $4.4 \mathrm{~g} / \mathrm{L}$ Murashige-Skoog salts (Carolina Biological) and 10 $\mathrm{g} / \mathrm{L}$ sucrose (GibcoBRL) pH 5.7, $50 \mu \mathrm{g} / \mathrm{L}$ kanamycin A (Sigma) and 650 $\mu \mathrm{g} / \mathrm{L}$ alpha-napthaleneacetamide (NAM) (Sigma). The T-DNAs carrying both the $D s$ element and the $A c$ element also contain the indole acetamide hydrolase (IAAH) gene. This allows selection against plants containing the IAAH gene using NAM, consequently selecting against plants containing the T-DNAs. The Ds element contains a kanamycin resistance (nptll) gene allowing plants to be recovered with a $D s$ transposon reinserted some distance from the donor locus. Insertion on a different chromosome or recombination allows the $D$ s to segregate away from the donor locus, thereby enriching for unlinked transposition events. Since this procedure also selects against the Ac element, the insertion is immediately stabilized. The $D s$ elements carry the $\beta$ glucuronidase (GUS) reporter gene, preceded by multiple splice acceptor sites that allow the Ds element to behave as a gene trap (GT) (Sundaresan et al., 1995; Springer et al., 1995). The reporter gene (GUS) has no promoter, so that GUS gene expression can occur under the promoter of the gene disrupted by $D$ s only when GUS inserts within a transcribed chromosomal region, creating a transcriptional fusion. 
This feature permits the expression pattern of a tagged gene to be detected when the $D s$ element is inserted into a gene in the correct orientation. In practice, however, only $17 \%$ of the gene trap lines generated showed GUS-positive staining in our screen. Plants were grown on soil ED73 (Universal Erde) in a growth room with $70 \%$ relative humidity and a day-night cycle of $16 \mathrm{~h}$ light at $21^{\circ} \mathrm{C}$ and $8 \mathrm{~h}$ darkness at $18^{\circ} \mathrm{C}$. For crosses with dehiscent anthers, closed flower buds were emasculated 1 or 2 days before pollination.

\section{Segregation ratio distortion and semi-sterility analyses}

Mutations affecting the gametophytic phase of the life cycle were identified in a two-step screen for (i) reduced fertility (seed abortion or undeveloped ovules), and (ii) segregation ratio distortion as described (Moore et al., 1997; Page and Grossniklaus, 2002; Brukhin et al., 2005a). Non-functional megagametophytes failed to initiate seed development resulting in semi-sterility. These mutations are marked by the $D s$ element containing a gene conferring kanamycin resistance $\left(\mathrm{Kan}^{r}\right)$ such that $\mathrm{Kan}^{r}$ is transmitted at reduced frequency to the progeny (non-Mendelian segregation). Gametophytic lethals were identified by the presence of greater than $30 \%$ undeveloped ovules in green siliques. The viable progeny was tested for segregation ratio distortion on kanamycin-containing plates. Lethality in the gametophyte or in the embryo should result in reduced transmission of $\mathrm{Kan}^{\mathrm{r}}$ ranging from 1:1 to $2: 1$ kanamycin resistant to sensitive seedlings.

\section{Genetic transmission analyses}

Transmission efficiencies through male (TEM) and female (TEF) gametophytes were determined by reciprocal crosses to the wild type (Howden et al., 1998; Brukhin et al., 2005b). Transmission efficiency was calculated as $\mathrm{Kan}^{\mathrm{r}} / \mathrm{Kan}^{\mathrm{s}} \mathrm{X} 100 \%$; where $\mathrm{Kan}^{\mathrm{r}}$, are kanamycinresistant and $\mathrm{Kan}^{\mathrm{s}}$ kanamycin-sensitive seedlings, respectively.

\section{Detection of Ds number per gene trap (GT) transposant}

We assessed the number of $D$ s elements present in each line by the genomic Southern blotting technique prior to any genetic and cytological analyses. This was necessary to ensure that a mutant phenotype was generated by a single $D$ s insertion. Genomic DNA was extracted from the inflorescence of the candidate GT line. A homogenizer (Silamat S5, Vivadent) was used to grind the frozen tissue in the presence of 4 glass beads of 200-300 micron diameter (Sigma). The resultant powder was processed using the Nucleon Phytopure Kit (Amersham) according to the standard protocol. $5 \mu \mathrm{g}$ of genomic DNA was digested with EcoR1 endonuclease (Boehringer Mannheim) and the resultant fragments resolved on a $0.8 \%$ agarose gel. The fractionated fragments were then transferred to a nylon membrane (Boehringer Mannheim) using the capillary blotting method. A Ds-dig probe was produced by PCR amplification to allow the incorporation of digoxygenin-11-dUTP (Boehringer Mannheim) into the DNA probe. To generate the Ds-dig probe, primers FMI32361 (5'- ATCCCGTACCGACCGTTATCG-3') and FMI32360 (5'CGTGTGAATGTGTGATGC-3') were used for the dig-labelling reaction (Roche Applied Science) amplifying the 5' end of Ds from plasmid pWS31 (Sundaresan et al., 1995). Hybridization with the Ds-dig probe was performed overnight at $68^{\circ} \mathrm{C}$, followed by membrane washes performed at $2 \times 5$ min intervals at $68^{\circ} \mathrm{C}$ in W1 buffer (2x SSC, $0.1 \%$ SDS); $1 \times 15 \mathrm{~min}$ in W2 (0.2x SSC, $0.1 \%$ SDS), and W3 (0.1x SSC, $0.1 \%$ SDS). The probe was detected using the standard protocol for chemi-luminescence with the CPD-star substrate (Boehringer Mannheim). A banding pattern was visualized by exposure of the probed nylon membrane to a standard laboratory X-Ray film (Kodak).

\section{Identification of sequences flanking the Ds insertions}

Chromosomal sequences flanking the gene trap insertions were amplified by TAIL-PCR (thermal asymmetric interlaced PCR) according to Liu et al. (1995) with modifications described by Grossniklaus and colleagues (1998), using nested primers within the Ds borders (Ds3'-1: 5'-
ACC CGA CCG GAT CGT ATC GGT-3', Ds3'-2: 5'- CCG GTA TAT CCC GTT TTC G-3', Ds3'-3: 5'-GTT ACC GAC CGT TTT CAT CC-3, Ds5'-1: 5'CCG TTT ACC GTT TTG TAT ATC CCG-3', Ds5'-2: 5'-CGT TCC GTT TTC GTT TTT TAC C-3', Ds5'-3: 5'-GGT CGG TAC GGA ATT CTC CC3') and a degenerate primer (AD2: 5'-NGT CGA (G/C)(A/T)G ANA (A/ T)GA A-3'). TAIL-PCR products were purified using the QiaQuick kit (Qiagen), and then sequenced. For inverse PCR (iPCR), DNA was digested with BstYl for the identification of 5' end and Ncol for the 3'-end. Primers for detection of the 5'-end were as follows: B34: 5'-ACG GTC GGT ACG GGA TTT TCC CAT-3‘ (primary iPCR), 4447: 5‘-CCG TTT CCG TTC CGT TTT C-3' (nested iPCR), B35: 5'-TAT CGT ATA ACC GAT TTT GTT AGT TTT ATC-3‘ (primary and nested), and for 3'end: pr3‘end A1: 5'-CGA TTT CGA CTT TAA CCC GAC CGG AT-3‘ (primary), pr3'end A2: 5‘-TCG TTT TCG TTA CCG GTA TAT CCC GT-3‘ (nested), pr3'B: 5‘ GAC GGG AAC CGG TAT TTT TGT TCG GT-3، (primary and nested). Disrupted genes were physically mapped and aligned with the genomic sequence of Arabidopsis using the BLAST search algorithm (www.Arabidopsis.org). We examined the expression of the disrupted genes by Meta-Profile analysis of Genevestigator software (https:// www.genevestigator.ethz.ch/gv/index.jsp), which summarizes information accumulated from hundreds of microarray experiments (Hurz et al., 2008).

\section{Insertion lines from other collections}

SALK lines were ordered from the Salk Institute Genomic Analysis Laboratory La Jolla, California, through the Nottingham Arabidopsis Stock Centre NASC. Lines GT.100129, GT_5_48498, GT_5_74422, GT_5_105311, GT.100129 and SM_3.27652 were kindly obtained from the John Innes Centre, UK. Line une3 was kindly provided by Prof. V. Sundaresan, (University of California, Davis). Most of the insertion SALK and GT lines showing a reduced seed set phenotype related to the corresponding mutant were genotyped in order to confirm the disruption of the gene under study.

\section{Cytological analyses and image processing}

Morphological characterization was performed on ovules and seeds cleared with chloral hydrate following the protocol of Yadegari and colleagues (1994). Specimens were observed using a Leica DMR microscope (Leica Microsystems) under differential interference contrast (DIC) optics. For quantitative phenotypic analyses of embryo sac development under DIC optics, 80 to 140 ovules, two to five days after self-pollination, were scored for each mutant in order to obtain a representative average terminal phenotype. For DAPI staining flowers were kept in $70 \%$ ethanol followed by substitution with staining buffer: CyStain UV Precise $P$ (Partec $\mathrm{GmbH}$ ). DAPI fluorescence in pollen grains were visualized under the microscope Leica DM 6000. All images were processed by Adobe Photoshop 5.5 (Adobe Systems).

\section{Acknowledgements}

We thank Juan-Miguel Escobar-Restrepo (University of Zürich) for help with the interpretation of sequencing data. This work was supported by the University of Zürich, the EXOTIC project of Framework Program $V$ of the European Union, the Novartis Foundation, and grants of the Swiss National Science Foundation to UG. VB is grateful to the Kredit zur Förderung des akademischen Nachwuchses der Stiefel-Zangger-Stiftung for financial support. We wish to express our gratitude to Dr. Caroline Ford (Aberystwyth University) for the critical reading of this manuscript.

\section{References}

ALLEN, S.C., BARRETTt, C.M., RAY, N., ROBINSON, C. (2002). Essential cytoplasmic domains in the Escherichia coli TatC protein. J. Biol. Chem. 277: 10362 10366

BAYER, E. M., BOTTRILL, A. R., WALSHAW, J., VIGOROUX, M., NALDRETT, M. J., THOMAS, C.L., MAULE, A.J. (2006). Arabidopsis cell wall proteome defined 
using multidimensional protein identification technology. Plant Proteomics 6: 301-311.

BERNAL A.J., YOO C.M., MUTWIL M., JENSEN J.K., HOU G., BLAUKOPF C., SORENSEN I., BLANCAFLOR E.B., SCHELLER H.V., WILLATS W.G. (2008). Functional analysis of the cellulose synthase like genes CSLD1, CSLD2 and CSLD4 in tip growing Arabidopsis cells. Plant Physiology, 148: 1238-1253.

BOAVIDA, L.C., SHUAI, B., YU, H.J., PAGNUSSAT, G.C., SUNDARESAN, V., MCCORMICK, S. (2009). A collection of $D$ s insertional mutants associated with defects in male gametophyte development and function in Arabidopsis thaliana. Genetics, 181: 1369-1385.

BONHOMME, S., HORLOW, C., VEZON, D., DE LAISSARDIERE, S., GUYON A., et al. (1998). T-DNA mediated disruption of essential gametophytic genes in Arabidopsis is unexpectedly rare and cannot be inferred from segregation distortion alone. Mol.Gen. Genet. 260: 444-452.

BRUKHIN, V., CURTIS, M.D., GROSSNIKLAUS, U. (2005a). The angiosperm female gametophyte: no longer the forgotten generation. Current Science 89: 1844-1852.

BRUKHIN, V., GHEYSELINCK, J., GAGLIARDINI, V., GENSCHIK, P., GROSSNIKLAUS, U. (2005b). The RPN1 subunit of the $26 \mathrm{~S}$ proteasome in Arabidopsis is essential for embryogenesis. Plant Cell 17: 2723-2737.

BUDZISZEWSKI, G.J., LEWIS, S.P., GLOVER, L.W., REINEKE, J., JONES, G., et al. (2001). Arabidopsis genes essential for seedling viability: isolation of insertional mutants and molecular cloning. Genetics 159: 1765-1778.

BUSCHMANN, H., CHAN, J., SANCHEZ-PULIDO, L., ANDRADE-NAVARRO, M.A., DOONAN, J.H., LLOYD, C.W. (2006). Microtubule-associated AIR9 recognizes the cortical division site at preprophase and cell-plate insertion. Curr. Biol. 16: 1938-1943.

CHRISTENSEN, C. A., KING, E.J., JORDAN, J.R., DREWS, G.N. (1997). Megagametogenesis in Arabidopsis wild type and the Gf mutant. Sex. Plant Reprod. 10: 49-64.

CHRISTENSEN, C. A., SUBRAMANIAN, S., DREWS, G. N. (1998). Identification of gametophytic mutations affecting female gametophyte development in Arabidopsis. Dev. Biol. 202: 136-151.

CHRISTENSEN, C.A., GORSICH, S.W., BROWN, R.H., JONES, L.G., BROWN, J., SHAW, J.M., DREWS, G.N. (2002). Mitochondrial GFA2 is required for synergid cell death in Arabidopsis. Plant Cell 14: 2215-2232.

DEN ELZEN, N., PINES, J. (2001). Cyclin a is destroyed in prometaphase and can delay chromosome alignment and anaphase. J. Cell Biol. 153: 121-135.

DRESSELHAUS T. 2006 Cell-cell communication during double fertilization. Curr Opin Plant Biol. 9: 41-47.

DREWS, G. N., LEE, D., CHRISTENSEN, C.A. (1998). Genetic analysis of female gametophyte development and function. Plant Cell 10: 5-17.

ESCOBAR-RESTREPO, J.M., HUCK, N., KESSLER, S., GAGLIARDINI, V., GHEYSELINCK, J., YANG, W.C., GROSSNIKLAUS, U. (2007). The FERONIA receptor-like kinase mediates male-female interactions during pollen tube reception. Science 317: 656-860.

FELDMANN, K. A., COURY, D. A., CHISTIANSON, M.L. (1997). Exceptional segregation of a selectable marker (KanR) in Arabidopsis identifies genes important for gametophytic growth and development. Genetics 147: 1411-22.

GALLOIS, J.L., GUYON-DEBAST, A., LÉCUREUIL, A., VEZON, D., CARPENTIER, V., BONHOMME, S., GUERCHE, P. (2009). The Arabidopsis proteasome RPT5 subunits are essential for gametophyte development and show accession-dependent redundancy. The Plant Cell, 21(2): 442-459.

GRINI, P. E., SCHNITTGER, A., SCHWARZ, H., ZIMMERMANN, I., SCHWAB, B., et al. (1999). Isolation of ethyl methanesulfonate-induced gametophytic mutants in Arabidopsis thaliana by a segregation distortion assay using the multimarker chromosome 1. Genetics 151: 849-863.

GROSSNIKLAUS, U., SCHNEITZ, K. (1998). The molecular and genetic basis of ovule and megagametophyte development. Seminars in Cell \& Developmental Biology 9: 227-238.

GROSSNIKLAUS, U., VIELLE-CALZADA, J. P., HOEPPNER, M. A., GAGLIANO, W. B. (1998). Maternal control of embryogenesis by MEDEA, a polycomb group gene in Arabidopsis. Science 280: 446-450.

HESLOP-HARRISON, J. (1979). The forgotten generation: some thoughts on the genetics and physiology of angiosperm gametophytes. The Bateson Lecture: Proceedings of the Fourth John Innes Symposium, pp. 1-14.
HOWDEN, R., S., PARK, K., MOORE, J. M., ORME, J., GROSSNIKLAUS, U. et al.,1998). Selection of T-DNA-tagged male and female gametophytic mutants by segregation distortion in Arabidopsis. Genetics 149: 621-631.

HRUZ, T., LAULE, O., SZABO, G., WESSENDORP, F., BLEULER, S., OERTLE, L., WIDMAYER, P., GRUISSEM, W., ZIMMERMANN, P. (2008). Genevestigator V3: a reference expression database for the meta-analysis of transcriptomes. Adv. Bioinformat 2008: 1-5.

JONES-RHOADES, M.W, BOREVITZ, J.O,, PREUSS, D. (2007). Genome-wide expression profiling of the Arabidopsis female gametophyte identifies families of small, secreted proteins. PLoS Genet. 3: 1848-1861.

JOHNSTON, A.J., MEIER, P., GHEYSELINCK, J., WUEST, S.E., FEDERER, M., SCHLAGENHAUF, E., BECKER, J.D., GROSSNIKLAUS, U. (2007). Genetic subtraction profiling identifies genes essential for Arabidopsis reproduction and reveals interaction between the female gametophyte and the maternal sporophyte. Genome Biol 8: 204-209.

KIPREOS E.T., PAGANO, M. 2000. The F-box protein family. Genome Biol. 1 (5), 3002.

LALANNE, E., MICHAELIDIS, C., MOORE, J.M., GAGLIANO, W., JOHNSON, A. et al. (2004). Analysis of transposon insertion mutants highlights the diversity of mechanisms underlying male progamic development in Arabidopsis. Genetics 167: 1975-1986.

LIU, Y. G., MITSUKAWA, N., OOSUMI, T., WHITTIER, R. F. (1995). Efficient isolation and mapping of Arabidopsis thaliana T-DNA insert junctions by thermal asymmetric interlaced PCR. Plant J. 8: 457-463.

MOORE, J. M., VIELLE CALZADA, J.-P., GAGLIANO, W., GROSSNIKLAUS, U. (1997). Genetic characterization of hadad, a mutant disrupting female gametogenesis in Arabidopsis thaliana. Cold Spring Harbor Symp. Quant. Biol. 62: 35-47.

MOORE, J. M. (2002). Isolation and characterization of gametophytic mutants in Arabidopsis thaliana. Ph.D. Thesis, State University of New York at Stony Brook, USA.

MOTOHASHI, R., NAGATA, N., ITO, T., TAKAHASHI, S., HOBO, T. et al. (2001). An essential role of a TatC homologue of a Delta $\mathrm{pH}$-dependent protein transporter in thylakoid membrane formation during chloroplast development in Arabidopsis Thaliana. Proc Natl Acad Sci USA 98: 10499-10504.

NEUTEBOOM, L. W., NG, J. M., KUYPER, M., CLIJDESDALE, O. R., HOOYKAAS, P. J., et al. (1999). Isolation and characterization of cDNA clones corresponding with mRNAs that accumulate during auxin-induced lateral root formation. Plant Mol. Biol. 39: 273-287.

OH S-A, PARK S-K, JANG I, MOORE JM, GROSSNIKLAUS U, TWELL D. (2003). halfman1, an Arabidopsis male gametophytic mutant associated with a $150 \mathrm{~kb}$ chromosomal deletion at the site of transposon insertion. Sex. Plant Reprod. 16: 99-102.

OLSEN, O.A. (2004). Nuclear endosperm development in cereals and Arabidopsis thaliana. Plant Cell, 16: 214-227.

PAGE, D.R., GROSSNIKLAUS, U. (2002). The art and design of genetic screens: Arabidopsis thaliana. Nat. Rev. Genet. 3: 124-136.

PAGE, D.R., KÖHLER, C., DA COSTA-NUNES, J.A., BAROUX, C., MOORE, J.M., GROSSNIKLAUS, U. (2004). Intrachromosomal excision of a hybrid Ds element induces large genomic deletions in Arabidopsis. Proc. Natl. Acad. Sci. USA 101: 2969-2974.

PAGNUSSAT, G.C., YU, H.J., NGO, Q.A., RAJANI, S., MAYALAGU, S. et al. 2005 Genetic and molecular identification of genes required for female gametophyte development and function in Arabidopsis. Development 132: 603-614.

PARINOV, S., SEVUGAN, M., YE, D., YANG, W.-C., KUMARAN, M., SUNDARESAN V. (1999). Analysis of flanking sequences from Dissociation insertion lines: a database for reverse genetics in Arabidopsis. Plant Cell 11: 2263-2270.

REDEI, G. P. (1965). Non-Mendelian megagametogenesis in Arabidopsis. Genetics, 51: 857-872.

SMALLE, J., VIERSTRA, R.D. (2004). The ubiquitin 26S proteasome protealitic pathway. Annu. Rev. Plant Physiol. Plant Mol. Biol. 55: 555-590.

SPRINGER, P. S., MCCOMBIE, W. R., SUNDARESAN, V., MARTIENSSEN, R. A. (1995). Gene trap tagging of prolifera, an essential Mcm2-3-5-like gene in Arabidopsis. Science, 268: 877-880.

STEFFEN, J.G., KANG, I.-H., MACFARLANE, J., DREWS, G.N. (2007). Identification of genes expressed in the Arabidopsis female gametophyte. Plant J. 5: 1281-1292. 


\section{V.B. Brukhin et al.}

SUNDARESAN, V., SPRINGER, P., VOLPE, T., HAWARD, S., JONES, J. D. et al. (1995). Patterns of gene action in plant development revealed by enhancer trap and gene trap transposable elements. Genes Dev. 9: 1797-1810.

TAKAHASHI, H., WATANABE-TAKAHASHI, A., SMITH, F. W., BLAKE-KALFF, M., HAWKESFORD, M. J., SAITO, K. (2000). The roles of three functional sulphate transporters involved in uptake and translocation of sulphate in Arabidopsis thaliana. Plant J. 23: 171-182.

VAN DER MERWE, J.A., DUBERY, I.A. (2007). Expression of mitochondrial tatC in Nicotiana tabacum is responsive to benzothiadiazole and salicylic acid. $J$. Plant Physiol. 164: 1231-1234.

VAN ENCKEVORT, L.J., DROC, G., PIFFANELLI, P., GRECO, R., GAGNEUR, C. (2005). EU-OSTID: a collection of transposon insertional mutants for functional genomics in rice. Plant Mol. Biol. 59: 99-110.

VIERSTRA, R.D. (2003). The ubiquitin/26S proteasome pathway, the complex last chapter in the life of many plant proteins. Trends Plant Sci. 68: 135-142.

WUEST S.E., VIJVERBERG K., SCHMIDT A, WEISS M., GHEYSELINCK J., LOHR M., WELLMER F., RAHNENFÜHRER J., VON MERING C., GROSSNIKLAUSU. (2010). Arabidopsis female gametophyte gene expression map reveals similarities between plant and animal gametes. Curr Biol. 20: 506512.
YADEGARI, R., PAIVA, G., LAUX, T., KOLTUNOW, A.M., APUYA, N., et al. (1994) Cell differentiation and morphogenesis are uncoupled in Arabidopsis raspberry embryos. Plant Cell 6: 1713-1729.

YADEGARI, R., DREWS, G.N. (2004). Female gametophyte development. Plant Cell 16: 133-141.

YANG, P., FU, H., WALKER, J., PAPA, C.M., SMALLE, J., et al. (2004). Purification of the Arabidopsis 26-S proteasome: biochemical and molecular analyses revealed the presence of multiple isoforms. J. Biol. Chem. 279: 6401-6413.

YEN, M. R., TSENG, Y. H., NGUYEN, E. H., WU, L. F., JR SAIER, M. H. (2002) Sequence and phylogenetic analyses of the twin-arginine targeting (Tat) protein export system. Arch. of Microbiol. 177: 441-450.

YU, H.J., HOGAN, P., SUNDARESAN, V. (2005). Analysis of the female gametophyte transcriptome of Arabidopsis by comparative expression profiling. Plant Physiol. 139: 1853-1869.

ZHANG, S., RAINA, S., LI, H., LI, J., DEC, E., MA, H., HUANG, H., FEDEROFF, N.V. (2003). Resources for targeted and deletional mutagenesis in Arabidopsis. Plant Molec. Biol. 53: 133-150.

ZYBAILOV, B., RUTSCHOW, H., FRISO, G., RUDELLA, A., EMANUELSSON, O., SUN, Q., VAN WIJK, K. J. (2008). Sorting signals, N-terminal modifications and abundance of the chloroplast proteome. PLOS ONE 3(4): 1994. 


\section{Further Related Reading, published previously in the Int. J. Dev. Biol.}

See our Special Issue Plant Development edited by José L. Micol and Miguel A. Blázquez at: http://www.ijdb.ehu.es/web/contents.php?vol=49\&issue=5-6

\section{Genetic analysis of reproductive development in tomato}

Rafael Lozano, Estela Giménez, Beatriz Cara, Juan Capel and Trinidad Angosto Int. J. Dev. Biol. (2009) 53: 1635-1648

Chromatin remodeling in plant development

José A. Jarillo, Manuel Piñeiro, Pilar Cubas and José M. Martínez-Zapater Int. J. Dev. Biol. (2009) 53: 1581-1596

Plant Developmental Biology in Spain: from the origins to our days and prospects for the future

José-Pío Beltrán

Int. J. Dev. Biol. (2009) 53: 1219-1234

Evolution and pleiotropy of TRITHORAX function in Arabidopsis Zoya Avramova

Int. J. Dev. Biol. (2009) 53: 371-381

Common themes in siRNA-mediated epigenetic silencing pathways André Verdel, Aurélia Vavasseur, Madalen Le Gorrec and Leila Touat-Todeschini Int. J. Dev. Biol. (2009) 53: 245-257

5 yr ISI Impact Factor $(2009)=3.253$

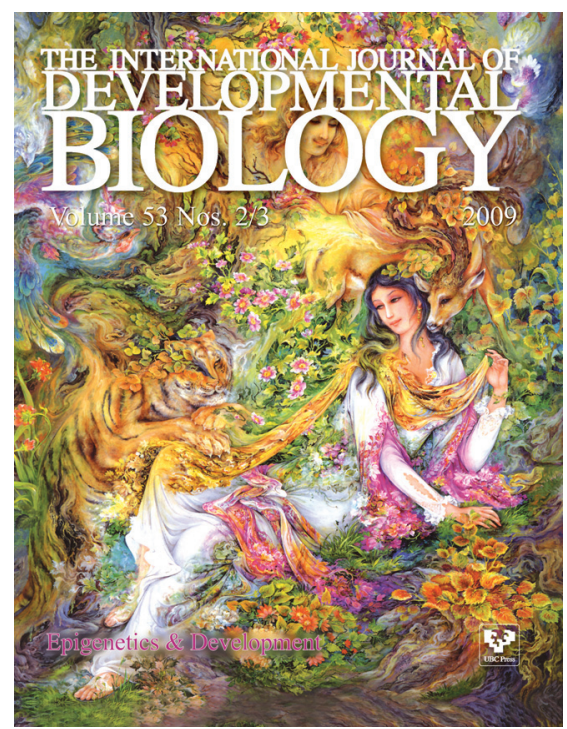

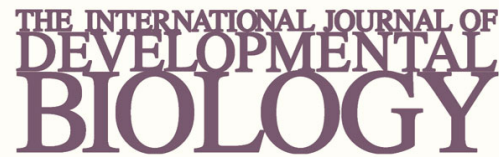

Volume 54 Nos. $6 / 7$
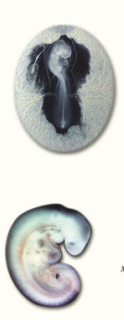

Developmental Hematopoiesis

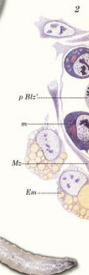

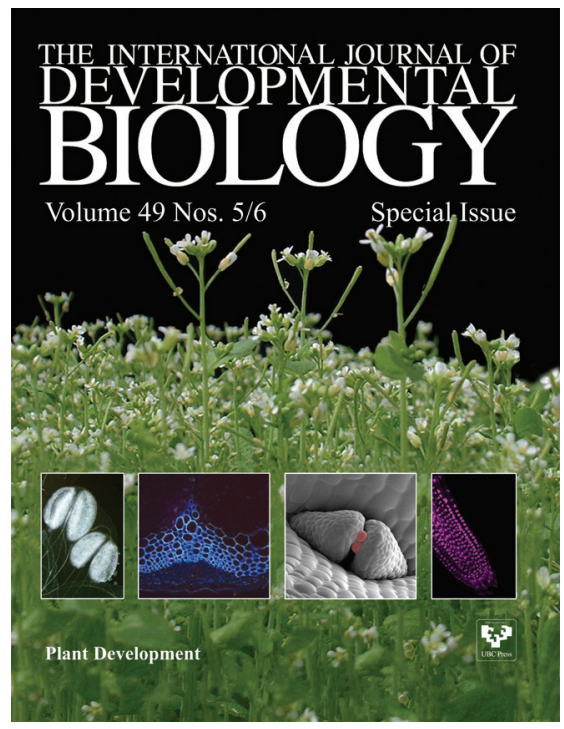

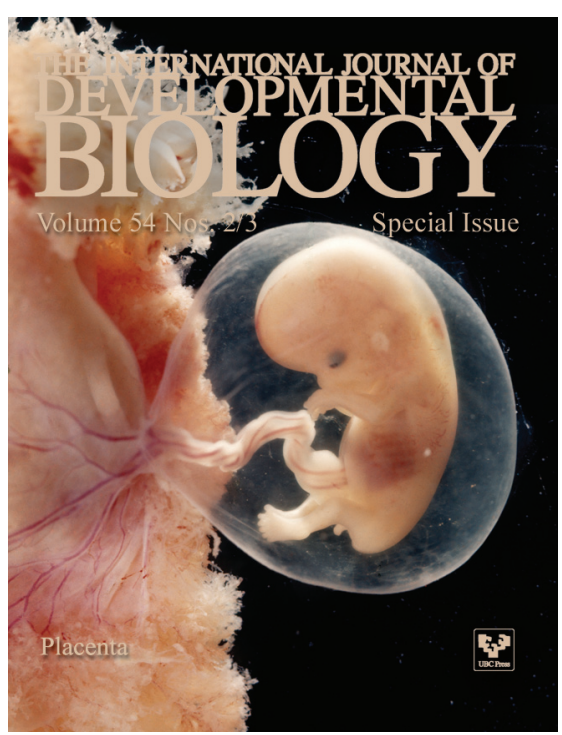

